\title{
Emissions pollutant from diesel, biodiesel and natural gas refuse collection vehicles in urban areas
}

\author{
José Ma López, Nuria Flores, Felipe Jiménez, Francisco Aparicio \\ Polytechnic University of Madrid (UPM), University Institute for Auto- \\ mobile Research
}

\begin{abstract}
Urban pollution is more and more concern due to human health implications. In that way, emissions pollutant from commercial vehicles which move daily at fixed itineraries such as, buses and refuse collection vehicles must be monitored. In this study we have aimed to show the results of the test made on refuse collection vehicles, in real conditions, with regard to their energy consumption and emissions pollutant.

A comparative study is carried out with regard to CO, HC, NOx, PM and greenhouse gas emissions, in respect of two types of engine with three different fuels. The fuels analyzed are diesel, biodiesel (B50 and B100) and compressed natural gas (CNG).
\end{abstract}

\section{Introduction}

The emission certification for heavy-duty applications is done by running engines in engine dynamometer, not with complete vehicle. The rationale for this is that a certain engine can be used for a number of different vehicle applications.

However, the interest to carry out dynamic emission testing with complete vehicles either on a chassis dynamometer or on the road is increasing. According to the current directives, the measurement of emissions for the official approval of Euro IV industrial vehicle diesel engines must be performed in accordance with three types of test: ESC, ELR y ETC.

- ESC: European Steady Cycle

- ELR: European Load Response Test 
2 Emissions pollutant form diesel, biodiesel and natural gas refuse collection vehicles in urban areas

- ETC: European Transient CycleThe maximum acceptable emission values for the above tests are shown in table 1 .

Table 1. Maximum acceptable emission figures for ESC, ELR and ETC tests on Euro IV industrial vehicles.

\begin{tabular}{|l|l|l|l|}
\hline \multirow{2}{*}{ EURO IV } & \multicolumn{2}{l|}{$\begin{array}{l}\text { European heavy-duty } \\
\text { emission limit values }\end{array}$} \\
\cline { 3 - 4 } & & ESC \& ELR & ETC \\
\hline CO & $\mathrm{g} / \mathrm{kWh}$ & 1.50 & 4.00 \\
\hline $\mathrm{HC}$ & $\mathrm{g} / \mathrm{kWh}$ & 0.46 & - \\
\hline NMHC & $\mathrm{g} / \mathrm{kWh}$ & - & 0.55 \\
\hline $\mathrm{CH} 4^{\mathrm{a}}$ & $\mathrm{g} / \mathrm{kWh}$ & - & 1.10 \\
\hline $\mathrm{NOx}$ & $\mathrm{g} / \mathrm{kWh}$ & 3.50 & 3.50 \\
\hline PM & $\mathrm{g} / \mathrm{kWh}$ & 0.02 & 0.03 \\
\hline Smokes & $\mathrm{m}-1$ & 0.50 & - \\
\hline
\end{tabular}

ESC European Steady Cycle, ELR European Load Response Test, ETC European Transient Cycle.

${ }^{\mathrm{a}}$ Only for CNG engines.

\section{Data Collection}

\section{Vehicles Description}

Table 2. Instrumented Trucks Specifications.

\begin{tabular}{|c|c|c|}
\hline & DIESEL TRUCK & CNG TRUCK \\
\hline Engine type & $\begin{array}{l}\text { Diesel engine (ID) } \\
\text { Turbocharged with inter- } \\
\text { cooler }\end{array}$ & $\begin{array}{l}\text { Otto engine } \\
\text { Turbocharged with inter- } \\
\text { cooler }\end{array}$ \\
\hline Displacement & $7790 \mathrm{~cm} 3$ & $7790 \mathrm{~cm} 3$ \\
\hline Cylinders & 6 , in line & 6 , in line \\
\hline Bore/ Stroke & $115 / 125 \mathrm{~mm}$ & $115 / 125 \mathrm{~mm}$ \\
\hline Compression ratio & $16: 1$ & $11.5: 1$ \\
\hline Engine Power Rating & $\begin{array}{l}228 \mathrm{~kW}(310 \mathrm{CV}) \\
\text { at } 1950-2400 \mathrm{rpm}\end{array}$ & $\begin{array}{l}200 \mathrm{~kW}(272 \mathrm{CV}) \\
\text { at } 1100-1800 \mathrm{rpm}\end{array}$ \\
\hline Engine Torque Rating & $\begin{array}{l}1300 \mathrm{Nm}(133 \mathrm{kgm}) \\
\text { at } 1200-1675 \mathrm{rpm}\end{array}$ & $\begin{array}{l}1100 \mathrm{Nm}(112 \mathrm{kgm}) \\
\text { at } 1100-1800 \mathrm{rpm}\end{array}$ \\
\hline Curb weight & $26000 \mathrm{~kg}$ & $26000 \mathrm{~kg}$ \\
\hline
\end{tabular}

The refuse collection trucks are lateral loaders. Due to the severe service operation high engine rating are required. The trucks used have difference 
power output, but the same curb weight. Some of the specifications for the instrumented trucks are presented in table 2 .

The CNG engine was turbocharged stoichiometric ratio with multipoint port fuel injection and equipped with a three-way catalyst.

\section{Measurement Equipment}

The "on-board" measurement equipment is an Horiba OBS 2200 device. It can acquire data under real-driving conditions of vehicle use. Such data are instantaneous and accumulated CO, CO2, THC and NOx emissions, fuel consumption and the speed at any one instant. Because of the set of gas analyzers, it provides real mass emission results $(\mathrm{g} / \mathrm{s})$ and instantaneous emissions (expressed as a \% or ppm, depending on the gases involved). The analyzers are:

- Multiple CO, CO2 and H2O analyzer based on the Heated NonDispersive Infrared Detection (HNDIR).

- THC analyzer based on the Heated Flame Ionization Detection (HFID).

- NOx analyzer based on the Heated Chemiluminescent Detection (HCLD).

The equipment also incorporates an exhaust gas flow meter that includes a calibrated pipe with its Pitot tubes, the sample gas outlet and the temperature sensor.

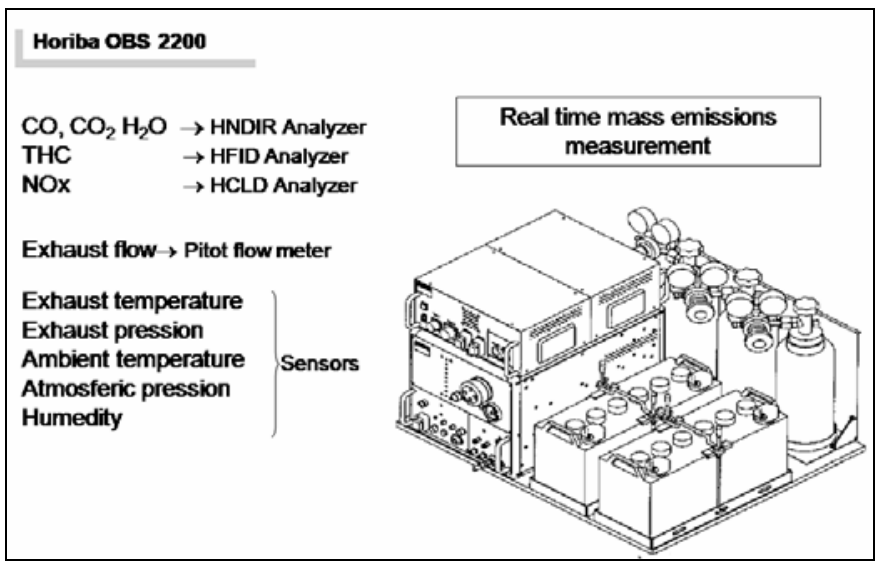

Fig. 1. Emissions measurement equipment Horiba OBS 2200.

By using the carbon balance method fuel consumption can be very accurately determined from the mass emissions of $\mathrm{CO}, \mathrm{CO} 2$ and THC. Also, 
4 Emissions pollutant form diesel, biodiesel and natural gas refuse collection vehicles in urban areas

given that the exhaust gas and fuel flow rate is known (calculated by carbon balance), the lambda factor can be accurately calculated.

The equipment also includes sensors for measuring humidity and ambient temperature and a GPS system for measuring the speed and position at every instant. It also has a laptop with specific software for system control, data collection and display and for generating test result reports.

Also integrated is an EIU (External Input Unit) with free analog ports to connect other equipment such as smoke opacity meters, thermocouples, etc. These analog inputs have allowed a MAHA particle measurement device to be connected. This device provides the amounts of particles in $\mathrm{mg} / \mathrm{m} 3$ measured by laser technology.

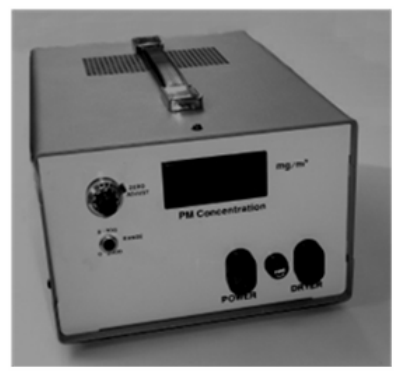

Fig. 2. MAHA particle measurement equipment.

The installation of the instrumentation equipment inside a vehicle is shown in the following images. Figure 3 shows the installation of the onboard emission measurement device - Horiba OBS 2200-, and the MAHA particle measurement equipment. The installation of the exhaust gas flow meter is also shown in figure 3, with its Pitot tubes, sample gas outlet and exhaust temperature sensor.
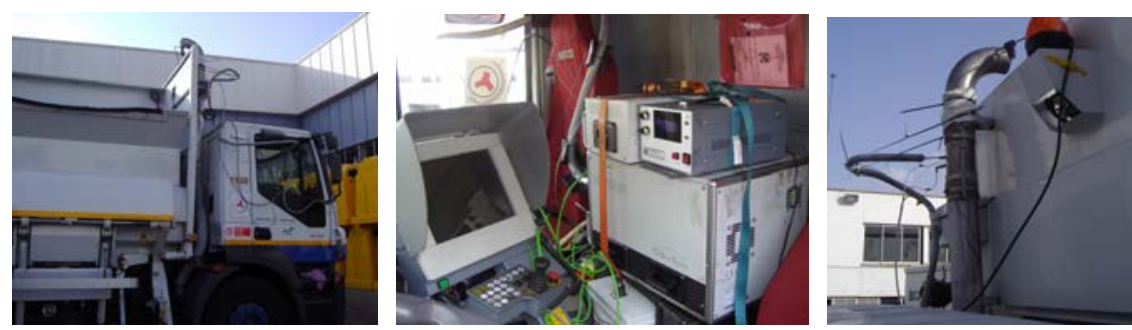

Fig. 3. Installation of the measurement equipment in a refuse truck with lateral loading. 
Analysis Methodology

On-board emissions measurements were conducted in real-world driving conditions on a specific driving route in the city of Madrid. Although chassis dynamometer drive cycles exits for heavy duty vehicles $[3,6]$, on-road test are being the field evaluation of the exhaust after-treatment system development, under real-world operating conditions in the vehicle $[1,4,7]$.

\section{Driving Cycle}

The first step in the analysis of data was the separation of in-use vehicle data into a number of distinct operational segments or categories specific to the refuse application. Figure 4 shows a sample of vehicle speed data based on which the operational categories were defined [2]. Route segment include:

- Approach

- Collection

- Transfer to Dump

- Dump

- Return

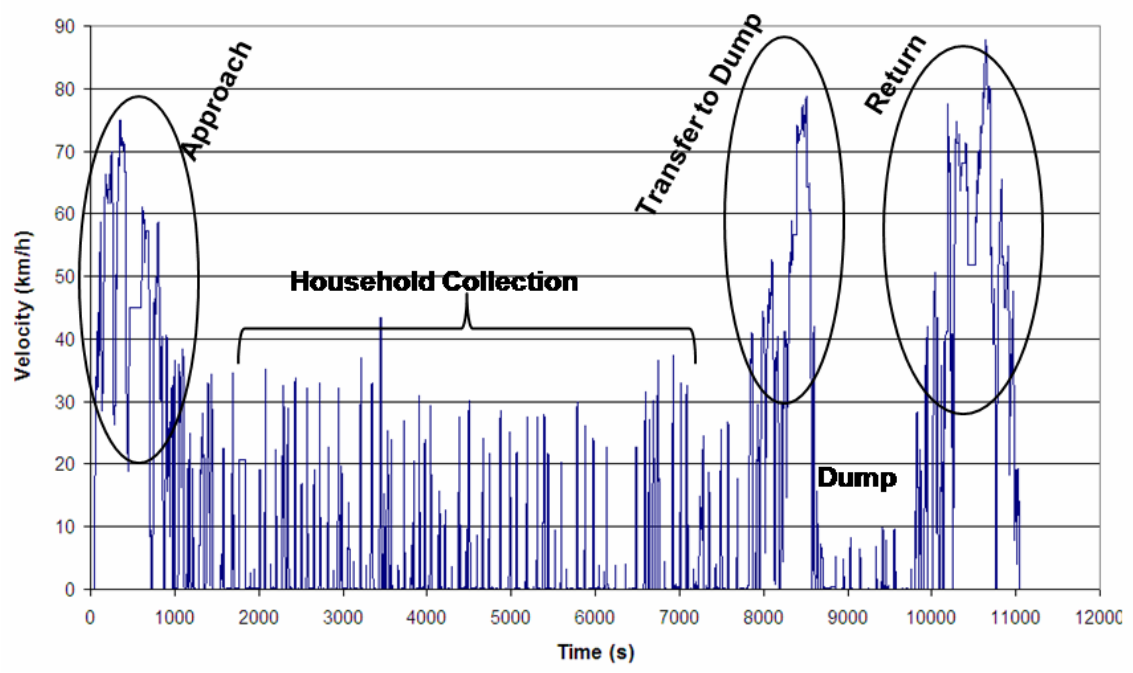

Fig. 4. Vehicle sample speed collection route data.

Data sequences for each segment were analyzed to determine their emission contributions. The characteristics of all the segments significantly differ. For example, the Approach, Transfer to Dump and Return segments 
6 Emissions pollutant form diesel, biodiesel and natural gas refuse collection vehicles in urban areas

involve no refuse compactions (i.e., no use of body hydraulics or powertake-off operation). Collection segment is a combination of kinematic and hydraulic operation. Dump category does not involve significant vehicle motion, basically power-take-off operation.

\section{Results}

The comparative study is carried out with regard to CO, HC, NOx, PM and $\mathrm{CO} 2$ emissions and fuel consumption for each segment of the driving cycle, in respect of two types of engine with three different fuels [5]. Figures 5 to 10 show the comparative results obtained in a real-world driving cycle emissions measurement.

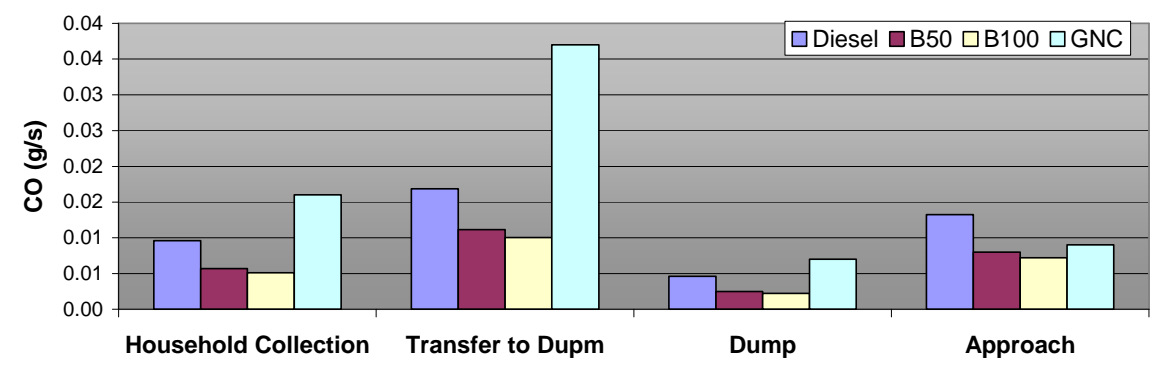

Fig. 5. CO emissions results.

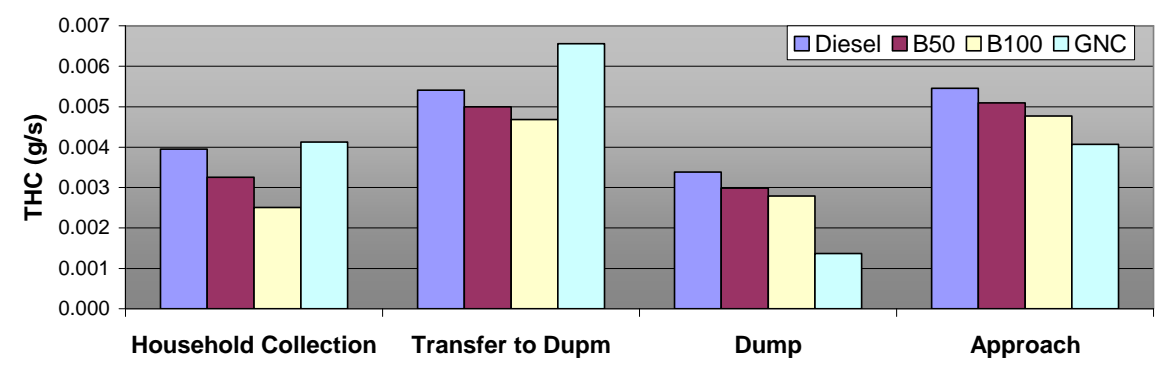

Fig. 6. THC emissions results. 


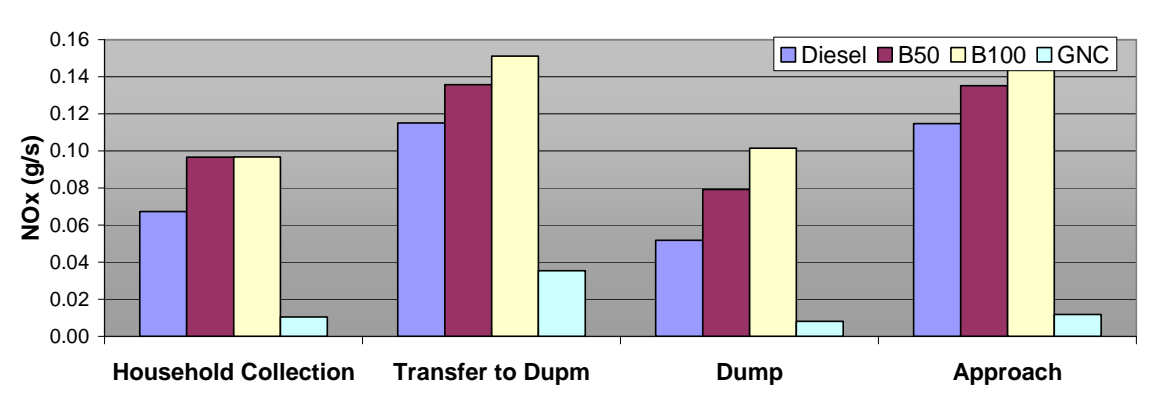

Fig. 7. NOx emissions results.

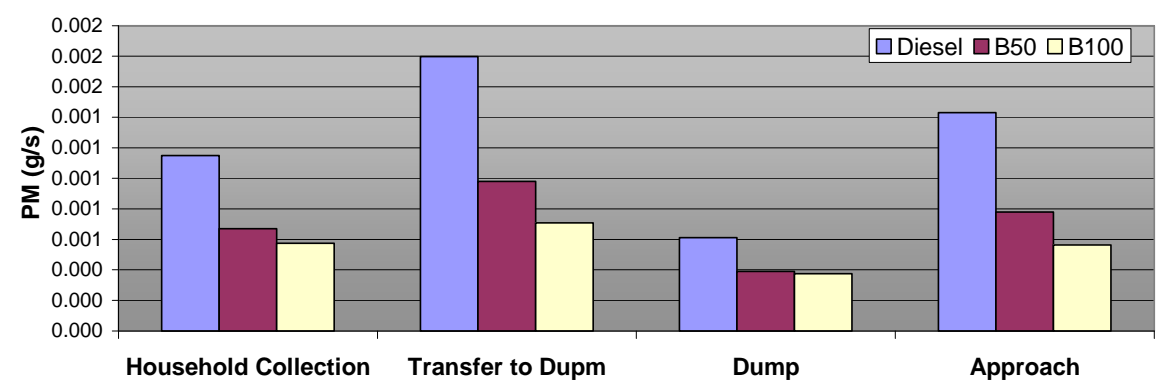

Fig. 8. PM emissions results.

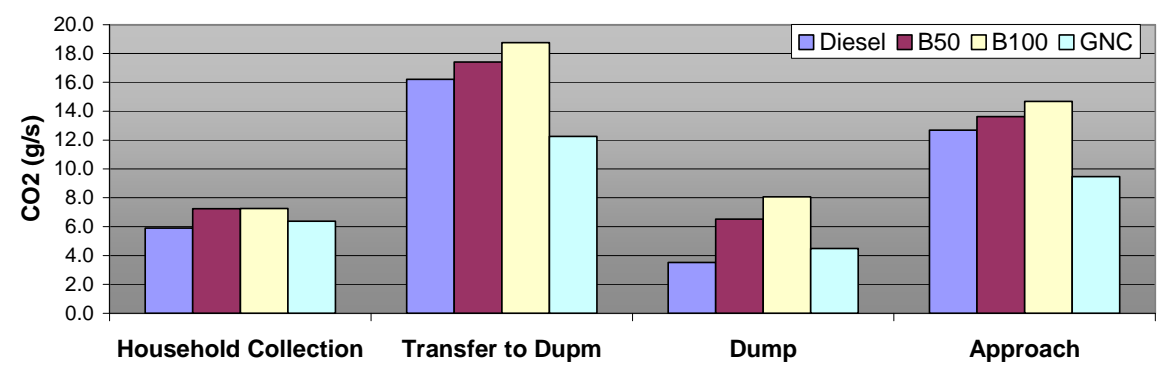

Fig. 9. CO2 emissions results.

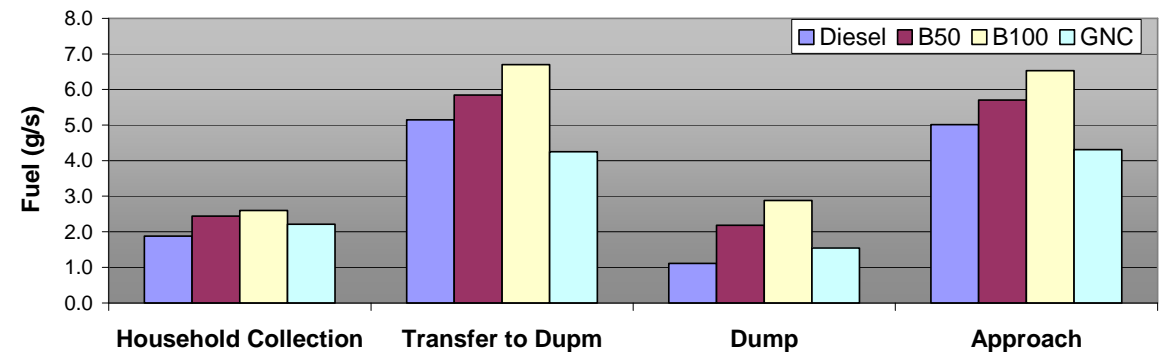

Fig. 10. Fuel consumption results. 
8 Emissions pollutant form diesel, biodiesel and natural gas refuse collection vehicles in urban areas

The results for $\mathrm{CO}$ are given in figure 5. CO emissions have decreased with increasing amount of methyl ester in the blend. The most notable decrease was demonstrated during Dump process. The CNG vehicle has higher $\mathrm{CO}$ emissions than the diesels.

Figure 6 presents tailpipe THC emissions. THC emissions have decreased with increasing amount of methyl ester in the blend. The differences among the selected segments are not relevant. The CNG vehicle had the same or even lower HC emissions than diesels except Transfer to Dump.

Figure 7 shows that the concentration of biodiesel increased into de base diesel NOx emissions presents a noticeable increase. The CNG vehicle has lower NOx emissions than the diesels.

The results for PM are given in figure 8. PM emissions have decreased with increasing amount of methyl ester in the blend. The most notable decrease was demonstrated during Dump process. The CNG vehicle no gave PM emissions.

Fossil fuel combustion is the main source in increasing global CO2 levels; witch is the consequence of greenhouse effect. Figure 9 shows the $\mathrm{CO} 2$ emissions in $\mathrm{g} / \mathrm{s}$ of the vehicle when operated under the driving cycle. It can be observed that $\mathrm{CO} 2$ was increased with increasing amount of methyl ester in the blend. The CNG vehicle has lower CO2 than the diesels during Transfer to Dump and Approach and slightly the same during the rest segments.

Fuel consumption presented an increase for biodiesel fuel blends in all categories. These results are calculated using a carbon balance and measure emission data. The heating value of the methyl ester and the blends was lower than the reference diesel fuel, while the density was higher. Since the fuel is delivered to the cylinders on a volumetric basis, a higher mass flow is pumped to the cylinders with the biodiesel blends for the same fuel volume.

Table 3 shows the results for complete driving cycle.

Table 3. Results for complete driving cycle.

\begin{tabular}{|l|l|l|l|l|l|}
\hline & & DIESEL & B50 & B100 & CNG \\
\hline CO & $\mathrm{g} / \mathrm{km}$ & 2.528 & 1.521 & 1.369 & 5.044 \\
\hline $\mathrm{HC}$ & $\mathrm{g} / \mathrm{km}$ & 1.009 & 0.857 & 0.699 & 1.151 \\
\hline $\mathrm{NOx}$ & $\mathrm{g} / \mathrm{km}$ & 18.185 & 24.783 & 25.538 & 3.807 \\
\hline $\mathrm{PM}$ & $\mathrm{g} / \mathrm{km}$ & 0.295 & 0.169 & 0.140 & - \\
\hline $\mathrm{CO} 2$ & $\mathrm{~g} / \mathrm{km}$ & 1859.067 & 2105.778 & 2164.077 & 2017.089 \\
\hline Fuel & $\mathrm{g} / \mathrm{km}$ & 590.535 & 731.727 & 801.550 & 698.318 \\
\hline
\end{tabular}




\section{Conclusions}

In this study have been presented the state-of-the-art data collection instrumentation and techniques to evaluate pollution emissions in real-world driving and will be used with proven data analysis procedure to develop a detailed drive cycle representative or residential refuse collection operation in the city of Madrid. This emission model will be very useful to compare complete fleet, different fuels and new technologies: advanced engines and hybrid configurations.

The experimental results may lead to the following conclusions:

- For Diesel vehicle, NOx and CO2 emissions increased with the addition of biodiesel when the vehicle operated over the specific driving test. CO, HC and PM emissions showed an opposite trend.

- For CNG vehicle, NOx and PM emissions were lower than diesels.

- Fuel consumption for the driving cycle was higher as the concentration of biodiesel in the blend increased. 
10 Emissions pollutant form diesel, biodiesel and natural gas refuse collection vehicles in urban areas

\section{References}

1. Frey H, Rouphail N, Zhai H, Farias T, Gonçalves G (2007) Comparing real-world fuel consumption for diesel-and hydrogen-fueled transit buses and implication for emissions: Transportation Research Part D 12 (2007) 281-291

2. Ivani Z (2007) Data Collection and Development of New York city Refuse Truck Duty Cycle: SAE Paper No. 2007-01-4118

3. Nylund N, Erkkilä K, Lappi M, Ikonen M (2004) Transit Bus Emission Study: Comparison of Emissions from Diesel and Natural Gas Buses: Research Report VTT 2004

4. Pelkmans L, Debal P (2006) Comparison of On-Road Emission with Emissions Measured on Chassis Dynamometer Test Cycles: Transportation Research Part D 11 (2006) 233-241

5. Tzirakis E, Karavulakis G, Zannikos F, Stournas S (2007) Impact of Diesel/Biodiesel Blends on Emissions from a Diesel Vehicle Operated in Real Driving conditions: SAE Paper No. 2007-01-0076

6. Walkowicz K, Proc K, Wayne S, Nine R, Campbell K, Wiedermeier G (2003) Chassis Dynamometer Emission Measurements from Refuse Trucks Using Dual-Fuel ${ }^{\mathrm{TM}}$ Natural Gas Engines: SAE Paper No. 200301-3366

7. Wang W, Gautam M, Sun X, Bata R, Clark N, Palmer M, Lyons D (1993) Emissions Comparisons of Twenty-six Heavy Duty Vehicles Operated on conventional and Alternative Fuels: SAE Paper No. 932952 